\title{
Development of Cyanine 813@Imidazole-Based Doped Supported Devices for Divalent Metal Ions Detection
}

\author{
Joana Galhano $^{1}\left(\mathbb{D}\right.$, Gonçalo A. Marcelo ${ }^{1} \mathbb{D}$, Hugo M. Santos ${ }^{1,2}$, José Luis Capelo-Martínez ${ }^{1,2} \mathbb{D}^{\mathbb{D}}$, \\ Carlos Lodeiro ${ }^{1,2}$ a and Elisabete Oliveira ${ }^{1,2, *(\mathbb{D})}$
}

1 BIOSCOPE Research Group, LAQV-REQUIMTE, Chemistry Department, NOVA School of Science and Technology, FCT-NOVA, Universidade NOVA de Lisboa, 1099-085 Lisbon, Portugal; j.galhano@campus.fct.unl.pt (J.G.); goncalo.marcelo9@gmail.com (G.A.M.); hmsantos@fct.unl.pt (H.M.S.); jlcm@fct.unl.pt (J.L.C.-M.); cle@fct.unl.pt (C.L.)

2 PROTEOMASS Scientific Society, Rua dos Inventores, Madam Parque, Caparica Campus, 2825-182 Caparica, Portugal

* Correspondence: ej.oliveira@fct.unl.pt

check for updates

Citation: Galhano, J.; Marcelo, G.A.; Santos, H.M.; Capelo-Martínez, J.L.; Lodeiro, C.; Oliveira, E. Development of Cyanine 813@Imidazole-Based Doped Supported Devices for Divalent Metal Ions Detection.

Chemosensors 2022, 10, 80.

https://doi.org/10.3390/ chemosensors 10020080

Academic Editor: Francesco Dell'Olio

Received: 6 January 2022

Accepted: 9 February 2022

Published: 14 February 2022

Publisher's Note: MDPI stays neutral with regard to jurisdictional claims in published maps and institutional affiliations.

Copyright: (C) 2022 by the authors. Licensee MDPI, Basel, Switzerland. This article is an open access article distributed under the terms and conditions of the Creative Commons Attribution (CC BY) license (https:// creativecommons.org/licenses/by/ $4.0 /)$.

\begin{abstract}
A NIR cyanine@imidazole derivative Cy1 was synthesized and evaluated as a metal ion sensor in solution. Cy1 was shown to be very sensitive to all metal ions tested, presenting a blue shift in the absorption from $668 \mathrm{~nm}$ to $633 \mathrm{~nm}$, followed by a change in colour from pale green to blue with $\mathrm{Zn}^{2+}, \mathrm{Cd}^{2+}, \mathrm{Co}^{2+}, \mathrm{Ni}^{2+}$ and $\mathrm{Hg}^{2+}$ ions. Despite the blue shift in the absorption, a decrease at $633 \mathrm{~nm}$ (with a colour change from pale green to colourless), as well as a quenching in the emission intensity at $785 \mathrm{~nm}$ were observed for $\mathrm{Cu}^{2+}$ ions. The results show the formation of sandwich complexes of two ligands per metal ion with the highest association constant observed for $\mathrm{Cu}^{2+}\left(\log \mathrm{K}_{\text {ass.abs }}=14.76 \pm 0.09 ; \mathrm{Log} \mathrm{K}_{\text {ass.emis. }}=14.79 \pm 0.06\right)$. The minimal detectable amounts were found to be $31 \mathrm{nM}$ and $37 \mathrm{nM}$, with a naked eye detection of $2.9 \mathrm{ppm}$ and $2.1 \mathrm{ppm} \mathrm{for} \mathrm{Hg}^{2+}$ and $\mathrm{Cu}^{2+}$ ions, respectively. These results prompted us to explore the applicability of $\mathbf{C y} \mathbf{1}$ by its combination with nanomaterials. Thus, Cy1@ doped MNs and Cy1@ doped PMMA nanoparticles were synthesized. Both nanosystems were shown to be very sensitive to $\mathrm{Cu}^{2+}$ ions in water, allowing a naked-eye detection of at least 1 ppm for Cy1@ doped MNs and 7 ppm for Cy1@ doped PMMA. This colourimetric response is an easy and inexpensive way to assess the presence of metals in aqueous media with no need for further instrumentation.
\end{abstract}

Keywords: cyanine@imidazole derivative; colourimetric; metal ions; PMMA nanoparticles; mesoporous silica nanoparticles

\section{Introduction}

The development of new methodologies for the detection of analytes in samples is an increasingly studied topic in the scientific community [1]. These methods are particularly important when detecting the presence of analytes in aqueous environments [2,3]. For example, levels of metal ions such as copper and cadmium, amongst others, in drinking water are very tightly regulated by governmental and non-governmental entities, since the presence of these metals above a particular concentration can cause severe health problems, once ingested $[4,5]$. The maximum allowable concentration (MAC) is a regulated unit that defines the maximum concentration of a particular analyte, present in drinking water [6]. These values can be described by governments or by other organizations, such as the World Health Organization (WHO) [7], or the European Union [8], and can be different, depending on the regulating unit. For example, the MAC for copper defined by the WHO is 2 ppm, a similar value to that described by the European Union; however, in the United States, this value is described as $1.3 \mathrm{ppm}$ [9]. Other examples include mercury ions by the same entities. The MACs for this analyte are 6, 2 and $1 \mathrm{ppb}$, defined by the WHO, United States Government and European Union respectively. These concentrations are usually in 
the ppm and ppb ranges and are generally determined by ICP-MES and FAAS [6], normally requiring sample treatment and expensive instrumentation.

Other methods can also be employed, from spectroscopic to electrochemical [6]. However, optical methods are possibly the simplest and cheapest ones employed for this purpose. These methods are usually produced by using a derivative that can interact specifically with the intended analytes, in a specific or non-specific way, and produce a colourimetric alteration that can be detected by either a simple naked-eye assessment or UV-VIS analysis $[10,11]$. This type of assessment is usually very intuitive, easy to implement, reasonably priced and most importantly, fast, making this type of chemosensor a very valuable tool. The main disadvantage that is reported for colourimetric methods is the lack of sensitivity [6]. Although these are usually very fast and effective, if the system is based on naked-eye detectable colorimetric alterations, a large concentration of the analyte might be required for a significant alteration. This may pose as a particularly limiting aspect, especially when considering metal detection in aqueous environments, due to their very low regulated concentrations.

The development of chemosensors for selective sensing of metal ions via visual changes have gained attention, especially ones with absorption and emission bands at the near-infrared region (NIR) $(650-1000 \mathrm{~nm})$ [12]. High sample penetration and reduced autofluorescence are some of the related advantages. Nevertheless, NIR-cyanine based probes for the detection of metal ions are scarce.

Cyanine dyes have incredible photophysical and photochemical characteristics, low toxicity, and excellent biocompatibility, making them an attractive platform for biological and environmental assays. These molecules are commonly characterized by presenting two nitrogen heterocyclic rings conjugated through an odd number of carbon atoms organized in a carbon chain, resulting in a positively charged molecule [13]. From this basis, a variety of cyanine types arise, based on the length of the carbon chain [14]. By varying the length of the chain it is possible to modify the absorptive and emissive characteristics of these molecules [15], allowing for an easy adaptation of their photophysical and photochemical characteristics. Due to their variety of traits and easy tunability, cyanine dyes can be employed in a wide variety of scientific fields, ranging from the photographic industry [16], to medical and clinical applications such as photo-thermal therapies [17].

Furthermore, metal-cyanine interactions are also widely reported in the literature, with a variety of systems for the detection of metals such as zinc, mercury and cadmium, amongst others [18-20]. However, the most widely known interaction of cyanine dyes is with copper ions, allowing also for the development of detection methods for these metals in a variety of environments [21].

Cyanine-analyte interactions can present colourimetric alterations, allowing for easy analysis and detection of the intended analyte in solution [22], making them ideal candidates as colourimetric probes for metal detection. Furthermore, these types of systems have the potential to detect concentrations in the ppm and ppb ranges, due to the high sensitivity that cyanine dyes present for metal ions in solution [23].

Cyanine derivatives can also be incorporated onto a solid-supported matrix [24,25], providing practicality for their application not only in laboratory environments but also in in situ applications. These types of devices can be particularly useful for environmental purposes, allowing for the detection of specific pollutants, and their possible capture in a combined approach.

Mesoporous silica nanoparticles are one type of soft matrix that has been widely studied throughout the past decade [26]. These nanoparticles, similar to cyanine derivatives, also present a wide variety of tunable properties, such as pore size and morphology, while also allowing for the loading and release of a wide variety of molecules [27]. As such, they can be employed in areas ranging from drug delivery [28] to metal remediation [29]. These particles have been reported as being able to capture metal ions in solution and entrap them as a very effective bioremediation strategy [30]. The combination of cyanine derivatives in mesoporous silica nanoparticles could produce a dye-doped system that 
would be inexpensive and simple to use for the detection of metals or other types of analytes. Furthermore, these devices could be easily employed in an in situ application, due to their increased stability.

Dye-doped polymer nanoparticles are another type of matrix that was revealed to be very efficient [31-33]. In this type of nanosystem, hydrophobic dyes can be easily incorporated, presenting outstanding features, such as higher photostability, efficient brightness and colour tunability [34].

Our goal in this work was to engineer cyanine-based doped supported devices for metal detection. For that, a NIR cyanine@imidazole dye, Cy1, was synthesized and their sensorial ability was evaluated in the presence of $\mathrm{Zn}^{2+}, \mathrm{Cd}^{2+}, \mathrm{Cu}^{2+}, \mathrm{Co}^{2+}, \mathrm{Ni}^{2+}$ and $\mathrm{Hg}^{2+}$ metal ions in acetonitrile. Cy1 was further incorporated onto MCM-41 type mesoporous silica and PMMA nanoparticles, enabling colourimetric metal detection in aqueous media.

\section{Materials and Methods}

\subsection{Chemicals and Materials}

Copper (II) trifluoromethanesulfonate $\left(\mathrm{Cu}(\mathrm{TfO})_{2},>98 \%\right)$, cadmium (II) trifluoromethanesulfonate $\left(\mathrm{Cd}(\mathrm{TfO})_{2},>98 \%\right)$, mercury (II) trifluoromethanesulfonate $\left(\mathrm{Hg}(\mathrm{TfO})_{2},>98 \%\right)$, nickel (II) trifluoromethanesulfonate $\left(\mathrm{Ni}(\mathrm{TfO})_{2},>98 \%\right)$, Cobalt (II) trifluoromethanesulfonate $\left(\mathrm{Co}(\mathrm{TfO})_{2},>98 \%\right)$, zinc (II) trifluoromethanesulfonate $\left(\mathrm{Zn}(\mathrm{TfO})_{2},>98 \%\right)$ were acquired from Solchemar. Methanol (MeOH), polymethyl methacrylate (PMMA), 1-(3Aminopropyl)imidazole, xexadecyltrimethylammonium bromide (CTAB) and tetrahydrofuran anhydrous (THF, >99.9\%), N,N-diisopropylethylamine (DIPEA) were purchased from Sigma Aldrich. IR-813 p-toluenesulfonate was acquired from TCI Chemicals. Acetonitrile $\left(\mathrm{CH}_{3} \mathrm{CN}\right)$ and dichloromethane $\left(\mathrm{CH}_{2} \mathrm{Cl}_{2}\right)$ were acquired from CarloErba. Dimethylsulfoxide (DMSO) was purchased from Panreac AppliChem. All solvents and reagents were of analytical reagent grade and were used as received.

\subsection{Instrumentation}

UV-Vis spectra were recorded on a JASCO V-650 spectrophotometer and fluorescence emission spectra on a HORIBA-JOBIN-YVON Fluoromax-4. Zeta potential and nanoparticle size distributions were measured in a Dynamic Light Scattering Malvern Nano Zetasizer, with a $633 \mathrm{~nm}$ laser diode (PROTEOMASS Scientific Society Facility, Caparica, Portugal). Infrared spectra (IR) were collected on an Alpha II Compact FT-IR spectrometer, FTIR-ATR (Bruker., Bremen, Germany), (PROTEOMASS Scientific Society Facility, Caparica, Portugal).

${ }^{1} \mathrm{H}$ NMR spectrum was recorded on a Bruker Avance III 400 at FCT-LAQV REQUIMTE Lab, University Nova of Lisbon, Portugal. The NMR spectrometers are part of The National NMR Facility, supported by Fundação para a Ciência e a Tecnologia (RECI/BBBBQB/0230/2012).

High-Resolution Mass Spectrometry analyses were carried out in the Laboratory for Biological Mass Spectrometry-Isabel Moura (PROTEOMASS Scientific Society Facility), using UHR ESI-Qq-TOF IMPACT HD (Bruker-Daltonics, Bremen, Germany).

\subsection{Synthesis of Cyanine Dye Cy813@Imidazol (Cy1)}

In a $100 \mathrm{~mL}$ round bottom flask, equipped with $\mathrm{CaCl}_{2}$ tube were added IR-813 p-toluenesulfonate (98 mg, $0.130 \mathrm{mmol})$, DIPEA $(30 \mu \mathrm{L}, 0.17 \mathrm{mmol})$ and $10 \mathrm{~mL}$ of $\mathrm{CH}_{2} \mathrm{Cl}_{2}$. 1-(3-Aminopropyl)imidazole $(44 \mu \mathrm{L}, 0.369 \mathrm{mmol})$ was then added and the reaction mixture was stirred for $48 \mathrm{~h}$ at room temperature. The solvent was evaporated under reduced pressure. The product was purified through chromatography (silica, eluent $\mathrm{CH}_{2} \mathrm{CL}_{2} / \mathrm{MeOH}$ 9:1). The final product $\mathbf{C y 1}$ was obtained as a dark green powder (yield: $56 \%$ ).

${ }^{1} \mathrm{NMR}\left(400 \mathrm{MHz}, \mathrm{CDCl}_{3}\right): \delta(\mathrm{ppm})=8.38(\mathrm{~d}, \mathrm{~J}=12 \mathrm{~Hz}, 2 \mathrm{H}, \mathrm{CH}), 8.04(\mathrm{~d}, \mathrm{~J}=8 \mathrm{~Hz}$, 2H, ArH), 7.89 (d, J = $8 \mathrm{~Hz}, 4 \mathrm{H}, \mathrm{ArH}), 7.77$ (m, 4H, ArH), $7.12(\mathrm{~d}, \mathrm{~J}=8 \mathrm{~Hz}, 2 \mathrm{H}, \mathrm{ArH})$, $7.05(\mathrm{~d}, \mathrm{~J}=8 \mathrm{~Hz}, 2 \mathrm{H}, \mathrm{CH}), 6.91(\mathrm{~d}, \mathrm{~J}=8 \mathrm{~Hz}, 1 \mathrm{H}, \mathrm{CH}), 6.22(\mathrm{~d}, \mathrm{~J}=12 \mathrm{~Hz}, 2 \mathrm{H}, \mathrm{CH}), 5.43$ $(\mathrm{t}, \mathrm{J}=13.6 \mathrm{~Hz}, 1 \mathrm{H}, \mathrm{NH}), 4.08\left(\mathrm{~m}, 2 \mathrm{H}, \mathrm{CH}_{2}\right), 3.77\left(\mathrm{~s}, 6 \mathrm{H}, \mathrm{CH}_{3}\right), 2.68\left(\mathrm{~m}, 2 \mathrm{H}, \mathrm{CH}_{2}\right), 2.55$ $\left(\mathrm{m}, 2 \mathrm{H}, \mathrm{CH}_{2}\right), 2.43\left(\mathrm{~m}, 4 \mathrm{H}, \mathrm{CH}_{2}\right), 1.99\left(\mathrm{~s}, 12 \mathrm{H}, \mathrm{CH}_{3}\right), 1.72\left(\mathrm{~m}, 2 \mathrm{H}, \mathrm{CH}_{2}\right)$. ESI-QqTOF 
MS: $\left[\mathrm{C}_{46} \mathrm{H}_{50} \mathrm{~N}_{5}\right]^{+}, 672.4061 \mathrm{~m} / \mathrm{z}$ (Error -1.0 ppm). FTIR $\left(\mathrm{cm}^{-1}\right): \mathrm{v}, 3100$ (=C-H stretch), 2925 (- $\left.\mathrm{CH}_{2}-\right), 1605$ (dienes), 1590, 1434 (Ar C-C stretch), 1540 (NH out of plane). UV-Vis in acetonitrile $(\lambda, \mathrm{nm})$ : band at $668 \mathrm{~nm}\left(\varepsilon=15,959 \mathrm{~cm}^{-1} \cdot \mathrm{M}^{-1}\right)$. Emission spectrum in acetonitrile $\left(\lambda_{\text {exc }}=668 \mathrm{~nm}, \lambda_{\text {emis. }}=785 \mathrm{~nm}\right)$.

\subsection{Synthesis of Cy1 Doped Mesoporous Silica Nanoparticles}

MCM-41 type mesoporous silica nanoparticles (MNs) were synthesized by an adaptation of the Stöber Method, already published by our group in [28]. The obtained mesoporous silica nanoparticles were then subjected to loading assays using the previously synthesized Cy813@imidazol derivative (Cy1). $50 \mathrm{mg}$ of MNs was incubated in $2 \mathrm{~mL}$ of a Cy1 acetonitrile solution. This solution was left overnight, under stirring, at room temperature, in a dark environment. The following day, the dye-doped MNs were recovered by centrifugation (10 min at 10,000 rpm) and washed several times with acetonitrile and Milli-Q $\mathrm{H}_{2} \mathrm{O}$. The obtained dye-doped MNs were left to dry in a silica chamber at room temperature and stored until further manipulation.

\subsection{Synthesis of $C y 1$ Doped Polymer Nanoparticles}

In a $4 \mathrm{~mL}$ glass vial, $150 \mathrm{mg}$ of PMMA were dissolved in THF, under stirring, at $50{ }^{\circ} \mathrm{C}$, until complete solubilization. $0.5 \mathrm{mg}$ of the cyanine dye Cy813@imidazol (Cy1) was also dissolved in $200 \mu \mathrm{L}$ of THF. Once PMMA is fully dissolved, the dye solution was added to the glass vial. Aqueous solutions of CTAB $(0 \mu \mathrm{M}, 10 \mu \mathrm{M}$ and $500 \mu \mathrm{M})$ were also prepared. $0.6 \mathrm{~mL}$ of the cyanine-PMMA THF solution were quickly added to $2.4 \mathrm{~mL}$ of the aqueous CTAB solutions. The obtained mixtures were left under stirring, at $50{ }^{\circ} \mathrm{C}$, for $15 \mathrm{~min}$. After this period, the solutions were filtered and stored in a dark environment, until further manipulation [32,33].

\subsection{Spectrophotometric and Spectrofluorometric Measurements}

The spectroscopic characterization and titrations were performed using stock solutions of the compounds (ca. $10^{-3} \mathrm{M}$ ) and prepared by dissolving the appropriate amount of dye $\mathbf{C y} \mathbf{1}$ in acetonitrile in a $5 \mathrm{~mL}$ volumetric flask. The final solutions were prepared by appropriate dilution of the stock solutions up to $10^{-5}-10^{-6} \mathrm{M}$. Titrations of Cy1 were performed by the addition of microliter amounts of standard solutions of $\mathrm{Cu}^{2+}, \mathrm{Cd}^{2+}, \mathrm{Hg}^{2+}$, $\mathrm{Ni}^{2+}, \mathrm{Co}^{2+}, \mathrm{Zn}^{2+}$ ions in acetonitrile. All measurements were performed at $298 \mathrm{~K}$.

The luminescence quantum yield of Cy1 was measured using a solution of IR-813 p-toluenesulfonate in ethanol $[\phi=0.060]$ as a standard [35-37]. All solvents used were of the highest purity Uvasol from Merck.

The final values were calculated using the equation:

$$
\Phi_{\mathrm{S}}=\Phi_{\text {std }}\left(\mathrm{I}_{\mathrm{S}} / \mathrm{I}_{\mathrm{std}}\right)\left(n_{\mathrm{S}} / n_{\text {std }}\right)^{2}
$$

$\Phi_{\mathrm{S}}$ and $\Phi_{\text {std }}$ are the radiative quantum yields of the sample and the standard, respectively, $n_{s}$ and $n_{\text {std }}$ are the refractive indexes of the sample and standard solutions (pure solvents were assumed), and $\mathrm{I}_{\mathrm{s}}$ and $\mathrm{I}_{\text {std }}$ are the respective areas of emission for sample and standard, respectively.

Characterization data of IR813 in ethanol: $\lambda_{\mathrm{abs}}=815 \mathrm{~nm}, \lambda_{\mathrm{emis}}=830 \mathrm{~nm}$, and $\phi_{\mathrm{F}}=0.060$. Characterization data of Cy1 in ethanol: $\lambda_{\text {abs. }}=678 \mathrm{~nm}, \lambda_{\text {emis. }}=785 \mathrm{~nm}$.

Cy1 encapsulation efficiency in mesoporous silica and PMMA nanoparticles were assessed via absorption spectra of the final products at their maximum at $633 \mathrm{~nm}$ and by mass balance.

Thus, the encapsulation efficiency $(E E \%)$ and the loading capacity $(\mathrm{mg} / \mathrm{g})$ were determined by the following equations $\left(t_{C y 1}\right.$ : the total amount of $\mathbf{C y 1} ; f_{C y 1}$ : amount of free Cy1).

$$
E E \%=\frac{t_{C y 1-f_{C y 1}}}{t_{C y 1}} \times 100 \text { loading capacity }\left(\frac{m g}{g}\right)=\frac{t_{C y 1}(m g)-f_{C y 1(m g)}}{\text { amount of nanoparticles or polymer }}
$$




\subsection{Determination of the Detection and Quantification Limits (LOD and LOQ)}

The detection limit (LOD) and quantification limit (LOQ) are the lowest concentration levels that can be detected and quantified to be statistically different from a blank. For the determination of LOD and LOQ, ten different measurements of a solution containing the selected probe were collected without the addition of any metal ion ( $\mathrm{y}_{\text {blank }}$ ). The LOD and LOQ were determined by the formulas:

$\mathrm{LOD}=\mathrm{y}_{\mathrm{dl}}=\mathrm{y}_{\text {blank }}+3 \mathrm{std}$, where $\mathrm{y}_{\mathrm{dl}}=$ signal detection limit and $\mathrm{std}=$ standard deviation . $\mathrm{LOQ}=\mathrm{y}_{\mathrm{dl}}=\mathrm{y}_{\mathrm{blank}}+10$ std, where $\mathrm{y}_{\mathrm{dl}}=$ signal detection limit and $\mathrm{std}=$ standard deviation .

Additionally, small amounts of the metal ion were added to a solution of the cyanine dye Cy1 to determine the minimal detectable and quantified concentration out of the LOD and LOQ values, respectively.

\subsection{Metal Sensing by Dye-Doped MNs}

A total of $2 \mathrm{mg}$ of the previously obtained dye-doped MNs was dispersed in $1 \mathrm{~mL}$ aqueous solutions containing $0,1,2.5,5,7.5,10,15$ and $20 \mathrm{ppm}$ of $\mathrm{Cu}^{2+}$ or $\mathrm{Hg}^{2+}$ for approximately $10 \mathrm{~min}$. Afterwards, the solubilized nanomaterials were recovered by centrifugation and left to dry overnight. The following day, a naked-eye colourimetric assessment was performed on the dried nanomaterials.

\subsection{Metal Sensing by Dye-Doped PMMA Nanoparticles}

Stock suspensions of Cy1 doped PMMA nanoparticles were diluted in water to yield 0.2 OD suspensions of $3 \mathrm{~mL}$ and spiked with 2, 5, 7, 10, 12, 14, 17, 19, 22, 24, 27, 29, 31, $34,36,42,48,54$ and $60 \mathrm{ppm}$ of $\mathrm{Cu}^{2+}$. The resulting suspensions were spectroscopically evaluated at 455, 630 and $668 \mathrm{~nm}$ and visually followed for any colourimetric changes. Naked-eye colourimetric changes towards $\mathrm{Zn}^{2+}, \mathrm{Cd}^{2+}, \mathrm{Cu}^{2+}, \mathrm{Co}^{2+}, \mathrm{Ni}^{2+}$ and $\mathrm{Hg}^{2+}$ metal ions were also evaluated by the addition of 20 equivalents of each metal ion in water.

\section{Results and Discussion}

\subsection{Synthesis and Characterization of Dye Cy1}

The synthesis of $\mathbf{C y} \mathbf{1}$ was designed by following the indications reported by Bouteiller and co-workers [38]. Cy1 was obtained by post-synthetic derivatization of the commercially available dye IR-813 p-toluenesulfonate through a $S_{\mathrm{RN} 1}$ reaction of its meso-chlorine atom with 1-(3-Aminopropyl)imidazole and DIPEA in dichloromethane at room temperature. Cy1 was obtained as a dark green powder with a yield of $56 \%$, and characterized by ${ }^{1} \mathrm{NMR}$, FTIR, Mass spectrometry (ESI-QqTOF), UV-vis and fluorescence emission spectroscopy, showing analytical data in accordance with its structure.

The absorption and emission spectra of dye Cy1 were measured at 295K in acetonitrile (see Figure 1). Cy1 shows in the absorption spectra a band at $668 \mathrm{~nm}$ with an $\varepsilon=15,959 \mathrm{~cm}^{-1}$. $\mathrm{M}^{-1}$ and an emission band at $785 \mathrm{~nm}$. The fluorescence quantum yield was determined using as a standard the IR-813 in ethanol, where a value of $\phi_{F}=0.33$ was calculated. It is evident that the introduction of an aminopropylimidazole moiety at the meso-chlorine atom led to a blue shift in absorption $(\Delta \lambda=137 \mathrm{~nm}$ in ethanol $)$ and emission $(\Delta \lambda=45 \mathrm{~nm}$ in ethanol) bands in comparison with the commercial dye IR813, which presents optical bands in the infrared region. In the same way, a 6-fold increase in the fluorescence quantum yield was verified, confirming that the introduction of aminopropyl linker between the imidazole unit and the heptamethine chain prevented the $\pi-\pi$ stacking interactions and thus aggregation, leading to fluorescent derivatives [38].

\subsection{Sensorial Ability towards Metal Ions}

The sensorial ability of $\mathbf{C y} \mathbf{1}$ towards $\mathrm{Zn}^{2+}, \mathrm{Cd}^{2+}, \mathrm{Cu}^{2+}, \mathrm{Co}^{2+}, \mathrm{Ni}^{2+}$ and $\mathrm{Hg}^{2+}$ metal ions was evaluated in acetonitrile. Similar spectral and colourimetric changes were observed for all metal ions except for $\mathrm{Cu}^{2+}$ metal ions (see Figure 2). As an example, Figure 2A shows the spectral behaviour of $\mathrm{Cy} \mathbf{1}$ upon the addition of $\mathrm{Zn}^{2+}$ metal ions. Figure $\mathrm{S} 3$ shows the 
absorption spectra of the titrations with the other metal ions. The increasing addition of this metal leads to a blue shift in the absorption band from $668 \mathrm{~nm}$ to $633 \mathrm{~nm}$, with a consequent change in colour from pale green to blue. Regarding emission spectra, no changes were observed upon the addition of $\mathrm{Zn}^{2+}, \mathrm{Cd}^{2+}, \mathrm{Co}^{2+}, \mathrm{Ni}^{2+}$ and $\mathrm{Hg}^{2+}$ metal ions.
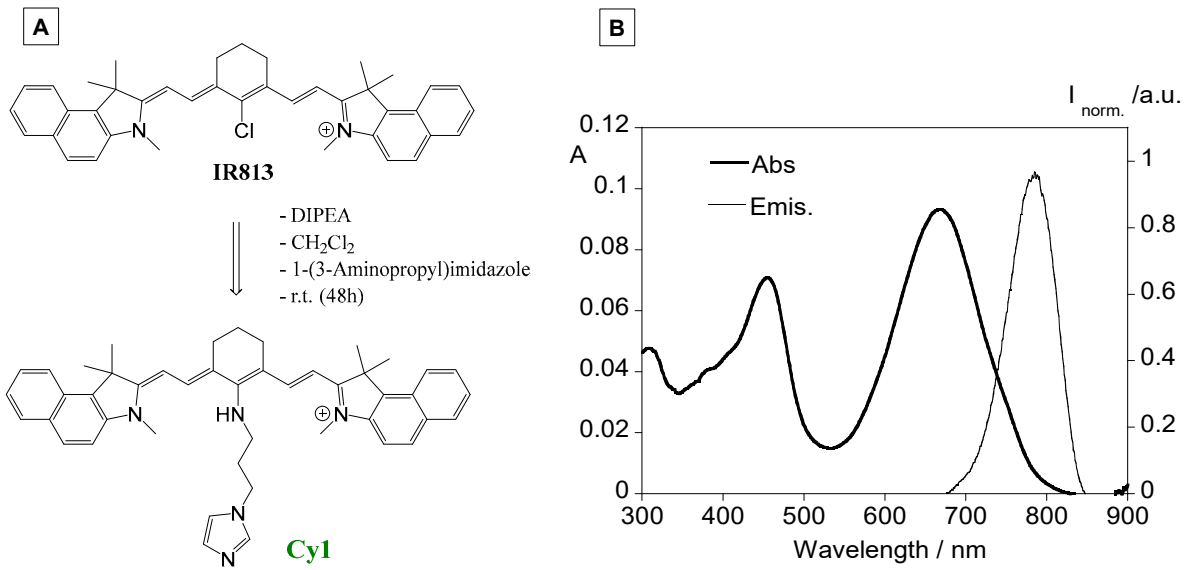

Figure 1. (A) General synthetic pathway for Cy1. (B) Absorption and emission spectra of Cy1 in acetonitrile. $[$ Cy1 $]=5.8 \times 10^{-6} \mathrm{M}, \lambda_{\text {exc. }}=668 \mathrm{~nm}$.
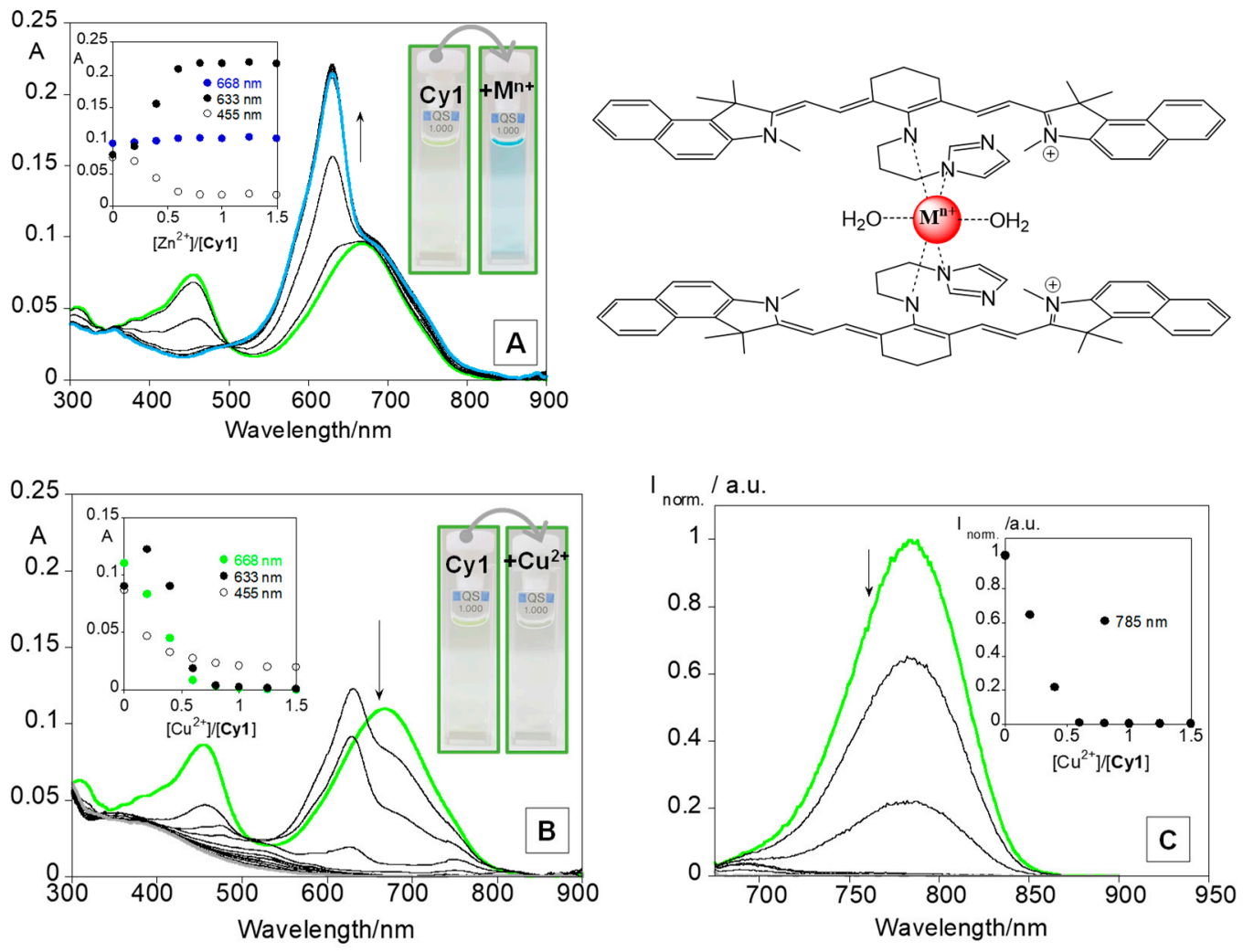

Figure 2. Spectrophotometric $(\mathbf{A}, \mathbf{B})$ titrations of dye $\mathbf{C y} 1$ with the addition of $\mathrm{Zn}^{2+}$ and $\mathrm{Cu}^{2+}$ in acetonitrile. The inset (A,B) represents the absorption at $455 \mathrm{~nm}, 633 \mathrm{~nm}$ and $668 \mathrm{~nm}$, as function of $\left[\mathrm{Zn}^{2+}\right] /[\mathbf{C y} 1]$ and $\left[\mathrm{Cu}^{2+}\right] /[\mathbf{C y} \mathbf{1}]$, respectively, and the colourimetric changes upon the addition of the different metal ions, $\mathrm{Cu}^{2+}$ and $\mathrm{M}^{\mathrm{n}+}: \mathrm{Zn}^{2+}, \mathrm{Cd}^{2+}, \mathrm{Co}^{2+}, \mathrm{Ni}^{2+}$ and $\mathrm{Hg}^{2+}$. $\left([\mathrm{Cy} 1]=5.8 \times 10^{-6} \mathrm{M}\right.$, $\lambda_{\text {exc }}=668 \mathrm{~nm}$, and $\left.\mathrm{T}=295 \mathrm{~K}\right)$. Spectrofluorimetric titration of $\mathrm{Cy1}(\mathrm{C})$ with the addition of $\mathrm{Cu}^{2+}$ in acetonitrile; the inset shows the emission at $785 \mathrm{~nm}$ as a function of $\left[\mathrm{Cu}^{2+}\right] /[\mathrm{Cy} 1]$. Proposed structure of the metal complexes for Cy1. 
On the other hand, the subsequent addition of $\mathrm{Cu}^{2+}$ ions to the $\mathrm{Cy} \mathbf{1}$ solution results in a shift of the absorption band from $668 \mathrm{~nm}$ to $633 \mathrm{~nm}$ followed by a gradual decrease in the absorption at $633 \mathrm{~nm}$. Moreover, colourimetric changes from pale green to blue and consequently to colourless were visualized. Furthermore, quenching on the emission intensity at $785 \mathrm{~nm}$ is also verified with $\mathrm{Cu}^{2+}$, due to its paramagnetic nature leading to non-radiative deactivation processes $[39,40]$.

The minimal detectable (MDA) and quantified (MQA) amounts of all metal ions were calculated using the equations in Section 2.7, and the values are listed in Table 1.

Table 1. Minimal detectable (MDA) and quantified amounts (MQA) of metal ions by Cy1. Stability association constants of $\mathbf{C y} \mathbf{1}$ with metal ions in acetonitrile ( $\sigma$ is an estimate of the average experimental error, ${ }^{\mathrm{a}}$ determined by absorption, ${ }^{\mathrm{b}}$ by emission).

\begin{tabular}{cccc}
\hline Metal (M) & MDA (nM) & MQA (nM) & Association Constants (LogKass.), $\sigma$ L:M \\
\hline $\mathrm{Zn}^{2+}$ & 39 & 77 & $12.68 \pm 0.16^{\mathrm{a}}(2: 1)^{\mathrm{a}}$ \\
\hline $\mathrm{Cu}^{2+}$ & 37 & 74 & $14.76 \pm 0.09^{\mathrm{a}} / 14.79 \pm 0.06^{\mathrm{b}}(2: 1)$ \\
\hline $\mathrm{Cd}^{2+}$ & 74 & 99 & $12.62 \pm 0.08^{\mathrm{a}}(2: 1)$ \\
\hline $\mathrm{Co}^{2+}$ & 65 & 87 & $12.80 \pm 0.01^{\mathrm{a}}(2: 1)$ \\
\hline $\mathrm{Ni}^{2+}$ & 56 & 93 & $12.08 \pm 0.02^{\mathrm{a}}(2: 1)$ \\
\hline $\mathrm{Hg}^{2+}$ & 31 & 62 & $14.05 \pm 0.06^{\mathrm{a}}(2: 1)$ \\
\hline
\end{tabular}

The lowest detectable and quantified amounts of $31 \mathrm{nM} ; 37$ and $62 \mathrm{nM} ; 74 \mathrm{nM}$ were determined for $\mathrm{Hg}^{2+}$ and $\mathrm{Cu}^{2+}$ ions, respectively (Table 1). Concerning the naked-eye detection, amounts of $5.9 \mu \mathrm{M}(2.1 \mathrm{ppm})$ and $5.8 \mu \mathrm{M}(2.9 \mathrm{ppm})$ were determined.

To better understand the interaction mode between Cy1 and the metal ions, the stoichiometry and the stability constants were calculated using the HypSpec program [41] and the main data are depicted in Table 1. The results show the formation of sandwich complexes of two ligands per metal ion with the highest association constants obtained for $\mathrm{Cu}^{2+}\left(\right.$ Log $\mathrm{K}_{\text {ass.abs }}=14.76 \pm 0.09 ;$ Log $\left.\mathrm{K}_{\text {ass.emis. }}=14.79 \pm 0.06\right)$ (see Figure S4). For the other metal ions, the association constants calculated present a similar order (LogK $K_{\text {ass. }} \approx 12-13$ ).

In order to improve the applicability of $\mathbf{C y} \mathbf{1}$ in aqueous media, the dye $\mathbf{C y} \mathbf{1}$ was incorporated into mesoporous silica and PMMA nanoparticles and further evaluated in aqueous solutions of known amounts of $\mathrm{Cu}^{2+}$ and $\mathrm{Hg}^{2+}$ metal ions.

\subsection{Cy1-Doped Mesoporous Silica Nanoparticles for Metal Sensing}

MCM-41 type mesoporous silica nanoparticles (MNs) were synthesized following an adapted protocol of the Stöber method, already described by our group [28]. For this synthesis approach, CTAB, a cationic surfactant, was selected as a template, and TEOS was used as a silica precursor. The precipitation of the silica precursor onto the micellar arrangement of CTAB in an aqueous solution originates the mesoporous silica shell. Other agents were added to the reactional mixture to promote monodispersity of the materials and control their morphologic characteristics, such as ethylene glycol and $\mathrm{NaOH}$, respectively. The template-containing nanoparticles were then obtained in a white powder composition. A template removal step was then performed to remove the cationic surfactant and obtain hollow mesoporous silica nanoparticles, allowing for the loading of diverse molecules onto their porous structure. This step was performed under mild conditions through incubation of the material in a methanolic ammonium nitrate solution and subsequent washes to remove all remaining unwanted molecules.

The effective removal of the template and synthesis of the material was evaluated through a FT-IR analysis (Figure S1). The acquired spectra is a typical spectra presented by mesoporous silica materials [42]. Peaks at $1057 \mathrm{~cm}^{-1}, 968 \mathrm{~cm}^{-1}$ and $795 \mathrm{~cm}^{-1}$ can be attributed to Si-O-Si, Si-O-H and Si-O vibrations, respectively $[42,43]$. At $3407 \mathrm{~cm}^{-1}$, a band can be attributed to $\mathrm{O}-\mathrm{H}$ vibrations. The morphologic characteristics of these materials can be further evaluated by TEM imaging (Figure S1). From here, it was possible to confirm the 
spherical mesoporous nature of the materials. Average particle size was also determined by TEM imaging, yielding a diameter of $30 \pm 6 \mathrm{~nm}$. Further characterization of these nanomaterials has already been reported by our group [28].

The incorporation of the cyanine derivative was evaluated through UV-Vis of the supernatant spectra, acquired during the washes following MNs-dye incubation. The loading percentage obtained for this incorporation was $92.15 \%$ and the encapsulation

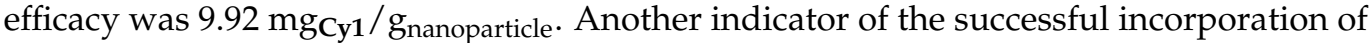
the dye onto the mesoporous matrix was a colourimetric alteration of the nanomaterial. The particles acquired a grey-dark blue colouration after the incorporation process (Figure 3).

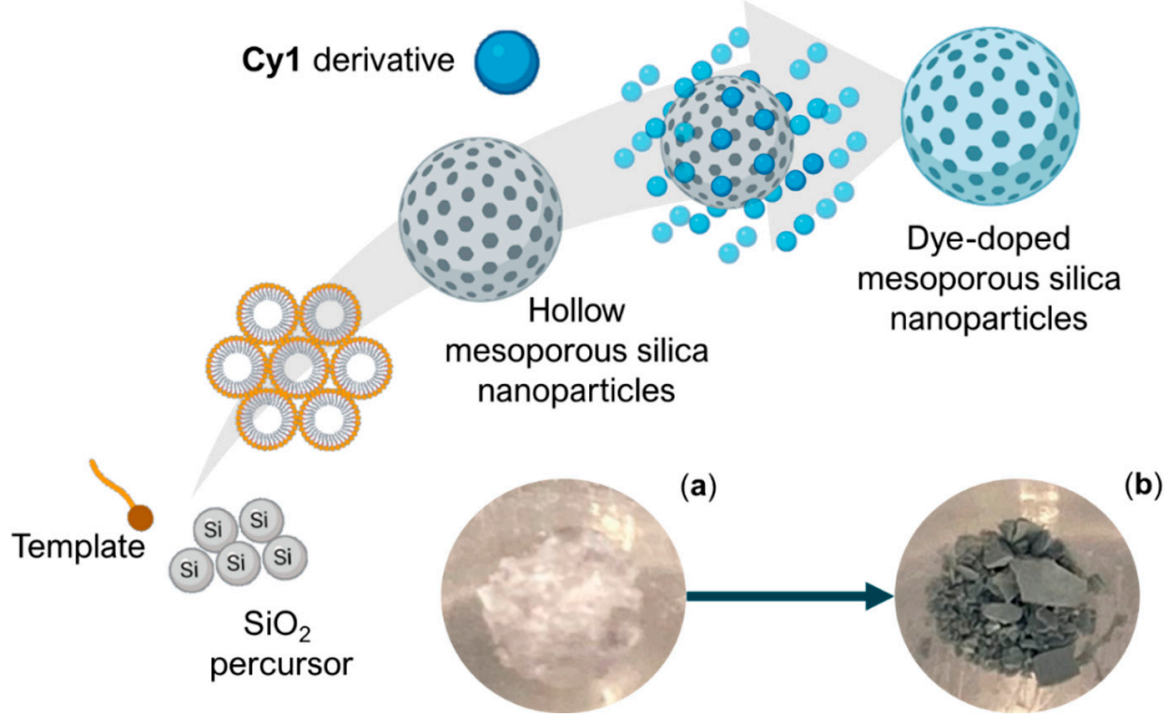

Figure 3. Schematic overview of the synthesis process of Cy1-doped mesoporous silica nanoparticles. Colourimetric alterations of mesoporous silica nanoparticles before (a) and after (b) Cy1 derivative incorporation.

The obtained dye-doped mesoporous silica nanoparticles were evaluated as a sensor for metal ions in aqueous solutions. Two metal ions were selected to this end: $\mathrm{Cu}^{2+}$ and $\mathrm{Hg}^{2+}$. A small amount of dye-doped MNs was incubated with aqueous solutions containing $0,1,2.5,5,7.5,10,15$ and 20 ppm of each respective metal for approximately $10 \mathrm{~min}$, after ensuring complete solubilization of the nanomaterial in solution. This timestamp was selected to ensure the complexation of the metals to the coordination sites in the dye. Afterwards, the nanomaterial was recovered by centrifugation and evaluated for any colourimetric alterations.

Whether no visible alterations were verified for $\mathrm{Hg}^{2+}$, a clear change was registered in the presence of $\mathrm{Cu}^{2+}$. Figure 4 shows the colourimetric profile obtained for each copper concentration. Nanomaterials maintained their greyish dark blue colouration when exposed to water without the presence of metals. Moreover, the respective aqueous supernatant did not present any colouration, indicating that the majority of the derivatives remained encapsulated, with no apparent signs of release to the medium. However, when exposed to copper concentrations, even as low as 1 ppm, slight colourimetric alterations were verified. After exposure to copper ions, the nanomaterial acquired a light brown tonality that became increasingly lighter up to $5 \mathrm{ppm}$ of $\mathrm{Cu}^{2+}$ and maintained that same colouration at higher copper concentrations.

Above 5 ppm, the colour presented by the dye-doped MNs is distinctly different than that presented by the nanomaterials without exposure to metals. This behaviour mirrors the results observed in solution by $\mathbf{C y} \mathbf{1}$ in the presence of $\mathrm{Cu}^{2+}$ ions. 


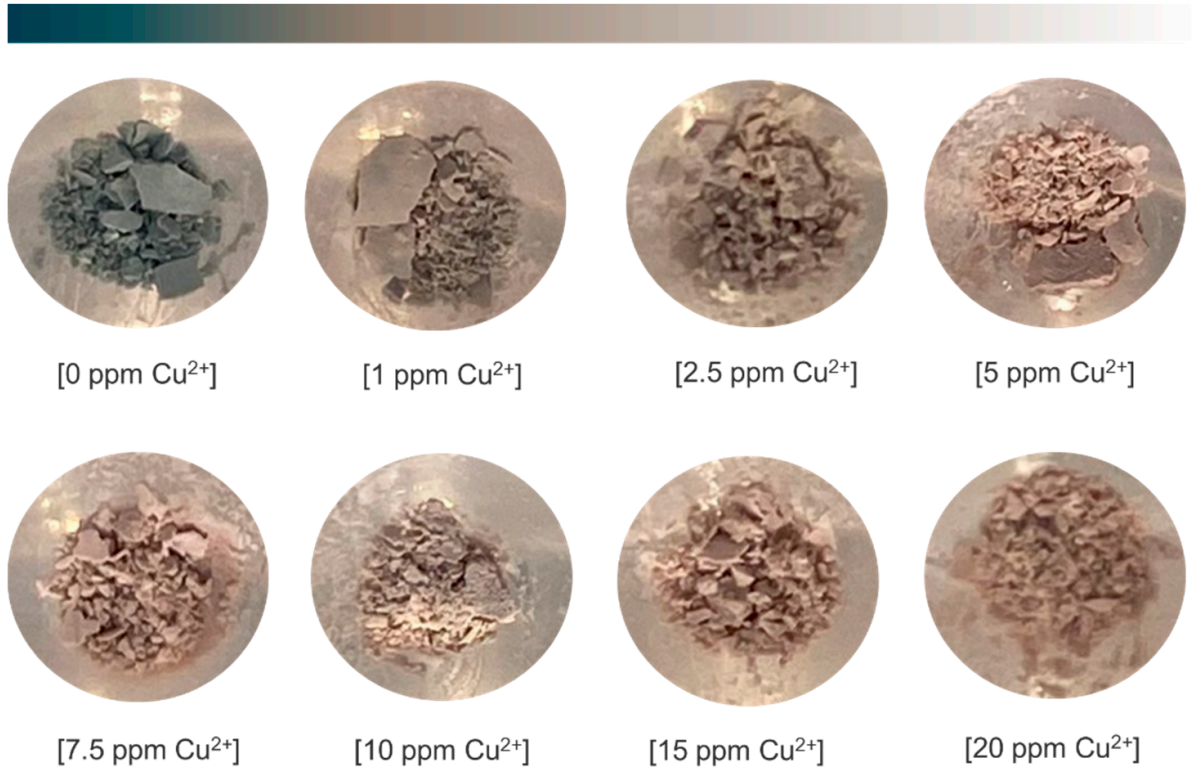

Figure 4. Colourimetric alterations of Cy1-doped $\mathrm{MNs}$ after $\mathrm{Cu}^{2+}$ exposure.

Dye-metal interaction mechanisms might follow a methodology proposed by Wang et al. [44]. Once a chromophore is incorporated onto a solid matrix, either through adsorption or electrostatic interactions, it retains its capacity to coordinate with metals. However, due to the immobilization of the chromophores onto the solid matrix, more coordination sites will be free to interact with the metal ions, thus increasing metal-chromophore interactions and, subsequently, the sensitivity of the system. These effects were also verified in the Cy1-doped MNs system, where the free Cy1 in acetonitrile solution allows a naked-eye detection of $2.1 \mathrm{ppm}$, and when immobilized into a mesoporous silica matrix, a naked-eye detection of at least $1 \mathrm{ppm}$ was observed in an aqueous solution. Thus, this system allows for the detection of very low concentrations of copper, at the ppm range, without the need for further instrumentation.

\subsection{Cy1-Doped PMMA Polymer Nanoparticles}

Cy1-doped PMMA nanoparticles were successfully obtained by an adaptation of an oil-in-water $(\mathrm{O} / \mathrm{W})$ synthetic protocol, previously published by the group [31]. The introduction of the oily THF solution, containing both polymer and Cy1, over a CTAB aqueous solution led to the formation of well-stabilized $\mathrm{O} / \mathrm{W}$ nanodroplets, which after THF evaporation induced PMMA reprecipitation and yielded the final polymeric particles (Figure 5).

The incorporation of Cy1 within PMMA nanoparticles was followed by UV-Vis spectroscopic analysis of the obtained suspension (at $\lambda=633 \mathrm{~nm}$ ) and confirmed by the presence of Cy1 typic absorption bands at 455, 633 and $668 \mathrm{~nm}$. Additionally, by comparing the spectra obtained for $0 \mu \mathrm{M}, 10 \mu \mathrm{M}$ and $500 \mu \mathrm{M}$ CTAB conditions, it was confirmed that Cy1 incorporation is determined by the concentration of $\mathrm{CTAB}$ in the aqueous phase (Figure 6). Maximum Cy1 incorporation was attained for $500 \mu \mathrm{M} \mathrm{CTAB}$, with the maximum amount of Cy1 entrapped in the PMMA matrix calculated to be $20.1 \mu \mathrm{g}(12.4 \mu \mathrm{M})$. This was translated into more intense absorbance peaks at 633 and $668 \mathrm{~nm}$ and a blue colouration (Figure 6a). The retention of the original Cy1 band centred at $668 \mathrm{~nm}$ for CTAB $500 \mu \mathrm{M}$ nanoparticles also supports the preferable encapsulation and protection of Cy1 within the PMMA matrix of the nanoparticles. This is contrary to the spectra obtained for $0 \mu \mathrm{M}$ and $10 \mu \mathrm{M}$ CTAB concentrations, where a coordination-like shift of the original Cy1 absorbance spectra, seen as a prevalence of the $633 \mathrm{~nm}$ peak (similar to those obtained during metal coordination), points towards some degree of deprotection and hydration of Cy1 molecules (Figures 6b,c and S6). 


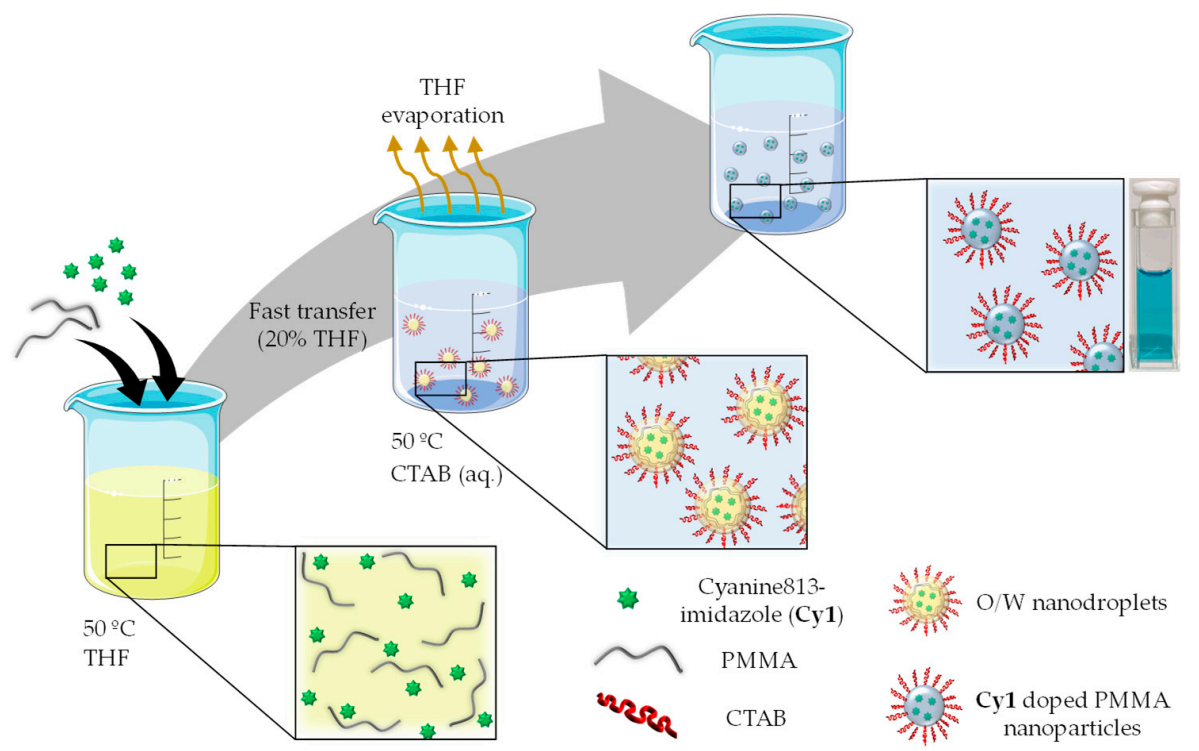

Figure 5. Synthesis of Cy1 doped PMMA nanoparticles.

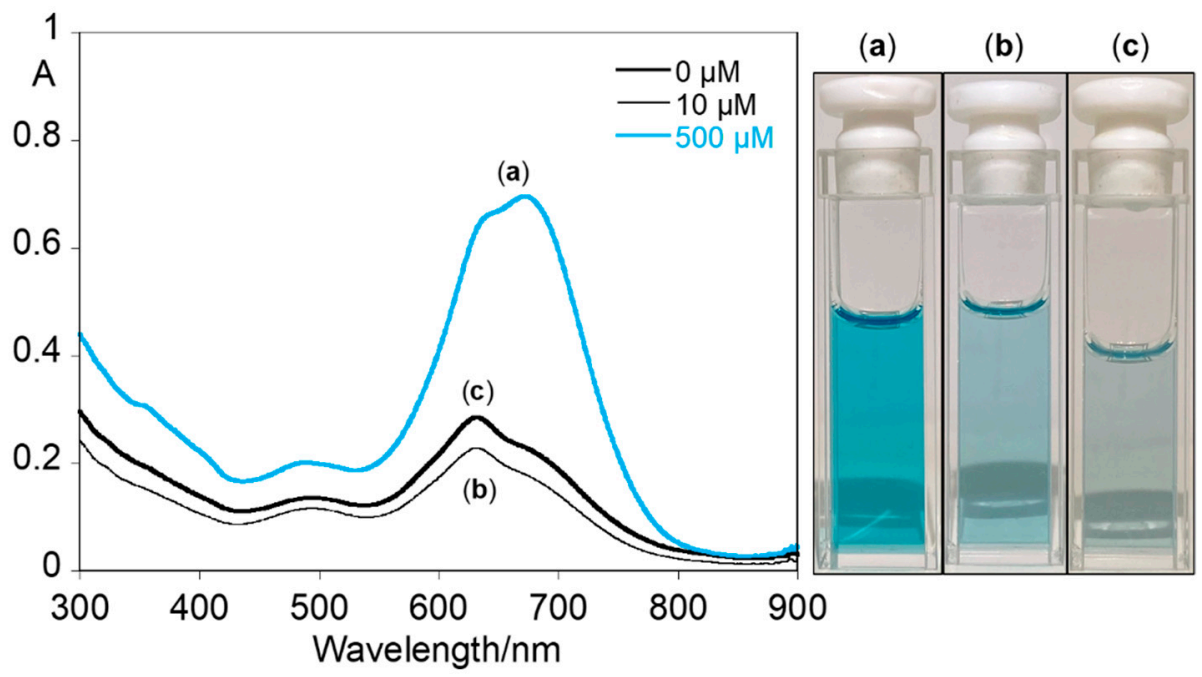

Figure 6. Absorption spectra and images of Cy1-doped PMMA nanoparticles synthesized with (a) 0 , (b) 10 and (c) $500 \mu \mathrm{M}$ of CTAB.

The CTAB Cy1-doped PMMA nanoparticles were obtained in the form of a stable blue aqueous dispersion, with those synthesized with $500 \mu \mathrm{M} \mathrm{CTAB}$ having an average hydrodynamic diameter of $272.5 \pm 3.8 \mathrm{~nm}(\mathrm{PDI}=0.202 \pm 0.019, \mathrm{n}=6)$. The stability of the final nanoparticles was assessed via their zeta potential, which shifted from ca. $-28 \mathrm{mV}$, for $0 \mu \mathrm{M} \mathrm{CTAB}$, to its maximum of $46 \pm 2 \mathrm{mV}$, for $500 \mu \mathrm{M} \mathrm{CTAB}$, as expected. FTIR analysis of the suspension obtained with $500 \mu \mathrm{M} \mathrm{CTAB}$ revealed, after subtraction of water peaks, the typical peaks of CTAB (2888 and $\left.1463 \mathrm{~cm}^{-1}\right)$ and PMMA (2997 and $\left.1192 \mathrm{~cm}^{-1}\right)$, as well as those corresponding to $=\mathrm{CH}$ bonding $\left(886 \mathrm{~cm}^{-1}\right)$ and the imidazole group (C-N stretch: $1041 \mathrm{~cm}^{-1}$ ) in Cy1 (Figure S2). Thus, the analysis confirmed the successful synthesis of Cy1-doped PMMA nanoparticles.

Due to their higher stability and Cy1 incorporation, only Cy1-doped PMMA nanoparticles obtained with $500 \mu \mathrm{M}$ CTAB were used in metal sensing studies. $\mathrm{Zn}^{2+}, \mathrm{Cd}^{2+}, \mathrm{Cu}^{2+}$, $\mathrm{Co}^{2+}, \mathrm{Ni}^{2+}$ and $\mathrm{Hg}^{2+}$ metal ions were tested, but only $\mathrm{Cu}^{2+}$ metal ions suggested a colourimetric selectivity, as solution studies in Cy1 (see Figures S5-S7). In the case of $\mathrm{Hg}^{2+}$ metal ions, the addition of 20 equivalents lead also to a change in colour from blue to purple, 
followed by the formation of a precipitate arising from nanoparticles aggregation. At lower concentrations of $\mathrm{Hg}^{2+}$ (up to 15 equivalents), such behaviour was not observed.

The sensorial ability of Cy1-doped PMMA nanoparticles towards $\mathrm{Cu}^{2+}$ metal ions in water was evaluated by titrating the nanoparticles suspension with small amounts of $\mathrm{Cu}^{2+}$ ions from a stock solution of $0.01 \mathrm{M}$. Absorption spectra were collected for all $\mathrm{Cu}^{2+}$ additions, from 0 to 33.3 equivalents, i.e., $\mathrm{Cu}^{2+}$ concentrations from 0 to $60 \mathrm{ppm}$. As can be perceived from Figure 7, even when inside the PMMA matrix, Cy1 is still sensitive towards $\mathrm{Cu}^{2+}$ ions, promoting $\mathrm{Cy} 1-\mathrm{Cu}^{2+}$ complexation and a subsequent decrease in the intensity of the peaks at 633 and $668 \mathrm{~nm}$. This phenomenon was accompanied by a total loss of colour, with the PMMA nanoparticles suspension changing from blue to colourless.

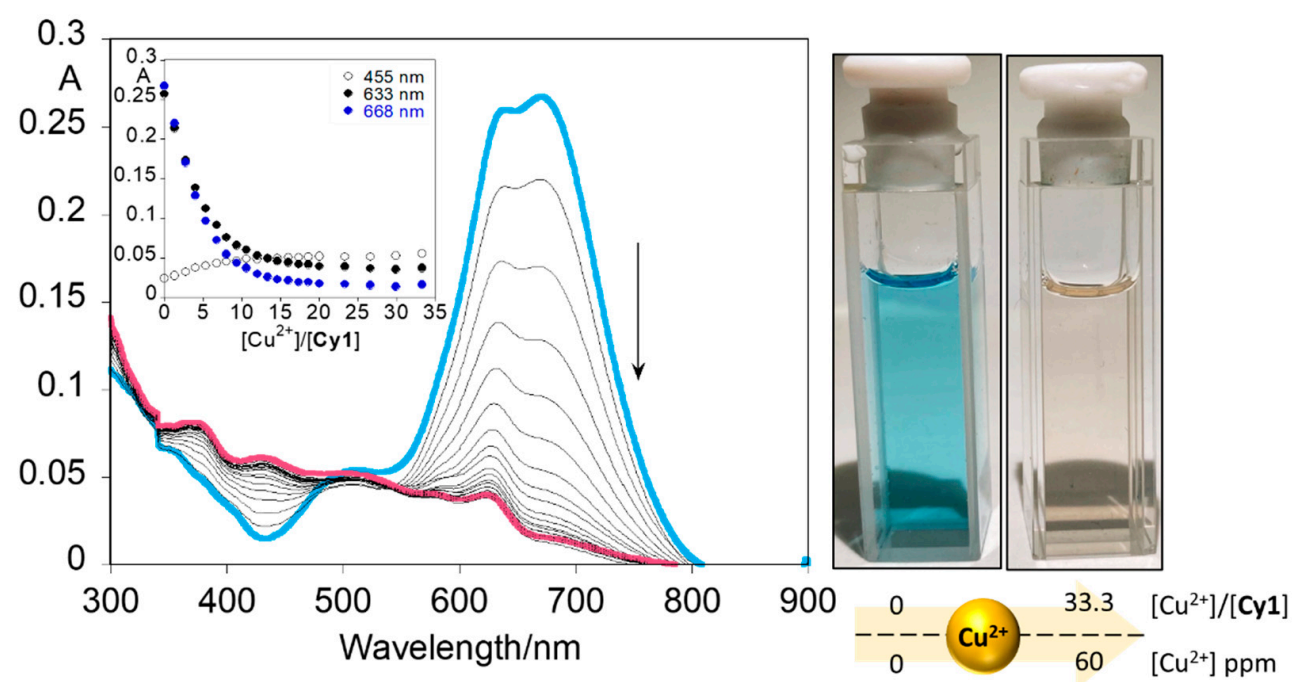

Figure 7. Absorption spectra of Cy1 doped PMMA nanoparticles (500 $\mu \mathrm{M}$ CTAB) and colourimetric aspect, in water, before and after titration, with increasing volumes of a $0.01 \mathrm{M} \mathrm{Cu}^{2+}$ aqueous solution from 0 to 33.3 equivalents ( 0 to 60 ppm, respectively); inset depicts absorption variations at 455, 633 and $668 \mathrm{~nm}$.

These results demonstrate that the incorporation of $\mathbf{C y} \mathbf{1}$ within the matrix of PMMA nanoparticles does not hinder the probe capacity to sense $\mathrm{Cu}^{2+}$, with $2 \mathrm{ppm}$ of $\mathrm{Cu}^{2+}$ ions inducing a significant $18 \%$ reduction in the intensity of Cy1's $668 \mathrm{~nm}$ peak. A 50\% reduction at $668 \mathrm{~nm}$ band intensity is obtained at just $7 \mathrm{ppm}$, whereas an almost total quenching is obtained at $22 \mathrm{ppm}$. These results are in line with the ones obtained for the mesoporous system, whose sensitivity is similar to that of the polymeric approach.

\section{Conclusions}

In summary, a cyanine@imidazole derivative Cy1 was successfully synthesized and employed for metal sensing in solution. Cy1 showed a colourimetric behaviour upon the addition of metal ions, with a colour change from pale green to blue in the presence of all tested metal ions except for $\mathrm{Cu}^{2+}$ ions, in which case a colour change from pale green to colourless was visualized. Stoichiometry of two ligands per metal ion was postulated for all ions, with the lowest detectable and quantified amounts obtained for $\mathrm{Cu}^{2+}$ and $\mathrm{Hg}^{2+}$ metal ions. Naked-eye detectable amounts of $2.1 \mathrm{ppm}$ and $2.9 \mathrm{ppm}$ were visualized for $\mathrm{Cu}^{2+}$ and $\mathrm{Hg}^{2+}$ ions in acetonitrile, respectively. Furthermore, Cy1 was successfully incorporated into mesoporous silica and PMMA nanoparticles, enabling metal detection in aqueous media. Cy1@ doped MNs and Cy1@ doped PMMA nanoparticles were shown to be very sensitive to $\mathrm{Cu}^{2+}$ ions in water, with similar colourimetric behaviour to that of the free $\mathbf{C y \mathbf { 1 }}$ in acetonitrile. Both systems allow for the detection of very low concentrations of copper, at the ppm range, without the need for further instrumentation. 
Supplementary Materials: The following supporting information can be downloaded at: https:/ / www.mdpi.com/article/10.3390/chemosensors10020080/s1, Figure S1: Mesoporous silica nanoparticle Characterization. (A) - TEM image of MNs, (B)_FT-IR spectra of MNs; Figure S2: FTIR spectra, after water subtraction, of the aqueous suspension of Cy1-doped PMMA nanoparticles, acquired with $500 \mu \mathrm{M} \mathrm{CTAB}$; Figure S3: Spectrophotometric titrations of dye Cy1 with the addition of $\mathrm{Cd}^{2+}$ (A), $\mathrm{Ni}^{2+}(\mathrm{B}), \mathrm{Co}^{2+}(\mathrm{C})$ and $\mathrm{Hg}^{2+}$ (D) in acetonitrile. The inset (A to D) represents the absorption at $455 \mathrm{~nm}, 633 \mathrm{~nm}$ and $668 \mathrm{~nm}$, as function of $\left[\mathrm{Cd}^{2+}\right] /[\mathrm{Cy1}],\left[\mathrm{Ni}^{2+}\right] /[\mathrm{Cy1}],\left[\mathrm{Co}^{2+}\right] /[\mathrm{Cy1}]$ and $\left[\mathrm{Hg}^{2+}\right] /[\mathrm{Cy} 1]$, respectively. $\left([\mathrm{Cy} 1]=5.8 \times 10^{-6} \mathrm{M}, \lambda_{\mathrm{exc}}=668 \mathrm{~nm}, \mathrm{~T}=295 \mathrm{~K}\right)$; Figure S4: Absorption (A) at $668 \mathrm{~nm}$ and emission (B) at $785 \mathrm{~nm}$ in acetonitrile, with the fitting determined by HypSpec Program, as function of $\left[\mathrm{Cu}^{2+}\right] /[\mathrm{Cy} 1](\mathrm{A}, \mathrm{B})$. $\left.[\mathrm{Cy1}]=5.8 \times 10^{-6} \mathrm{M}, \lambda_{\mathrm{exc}}=668 \mathrm{~nm}, \mathrm{~T}=295 \mathrm{~K}\right)$; Figure S5: Naked-eye assessment of the colourimetric selectivity of $\mathbf{C y} \mathbf{1}\left(1 \times 10^{-5} \mathrm{M}\right)$ for $\mathrm{Cu}^{2+}$ metal ions ( 0.5 equivalents) upon the addition of other metal ions (1 equivalent) in acetonitrile. $1-\mathrm{Cy} 1,2-\mathrm{Cy} 1+\mathrm{M}^{\mathrm{n}+}\left(\mathrm{Zn}^{2+}, \mathrm{Cd}^{2+}, \mathrm{Co}^{2+}, \mathrm{Ni}^{2+}\right.$ and $\left.\mathrm{Hg}^{2+}\right), 3-\mathrm{Cy} 1+\mathrm{Cu}^{2+}, 4-\mathrm{Cy} 1+\mathrm{Cu}^{2+}+\mathrm{Zn}^{2+}$, $5-\mathrm{Cy} 1+\mathrm{Cu}^{2+}+\mathrm{Cd}^{2+}, 6-\mathrm{Cy} 1+\mathrm{Cu}^{2+}+\mathrm{Co}^{2+}, 7-\mathrm{Cy} 1+\mathrm{Cu}^{2+}+\mathrm{Ni}^{2+}, 8-\mathrm{Cy} 1+\mathrm{Cu}^{2+}+\mathrm{Hg}^{2+} . \mathrm{A}$ and $B$ are duplicates; Figure S6: Naked-eye assessment of Cy1 $\left(1 \times 10^{-5} \mathrm{M}\right)$ in different ratios of acetonitrile $(\mathrm{ACN})$ and water $\left(\mathrm{H}_{2} \mathrm{O}\right)$. F and $\mathrm{G}$ are duplicates; Figure S7: Naked-eye image of Cy1@PMMA nanoparticles upon the addition of 20 equivalents of the metal ions in water.

Author Contributions: Conceptualization, E.O.; methodology, E.O.; validation, E.O., H.M.S. and C.L.; formal analysis, J.G., G.A.M., H.M.S. and E.O.; investigation, J.G., G.A.M., H.M.S. and E.O.; writing — original draft preparation, all authors; writing — review and editing, all authors; supervision, E.O.; project administration, E.O.; funding acquisition, E.O., H.M.S., J.L.C.-M. and C.L. All authors have read and agreed to the published version of the manuscript.

Funding: This work was supported by the Associate Laboratory for Green Chemistry-LAQV which was financed by national funds from FCT/MCTES (UIDB/50006/2020 and UIDP/50006/2020). PROTEOMASS Scientific Society is acknowledged for funding support (General Funding Grant), as well as for the funding provided to the Laboratory for Biological Mass Spectrometry Isabel Moura (\#PM001/2019 and \#PM003/2016). G.M thanks FCT/MCTES (Portugal) for his doctoral grant PD/BD/142865/2018. H.M.S. acknowledges FCT/MCTES (Portugal) for his research contract, FCT Investigator Program 2015 (IF/00007/2015). E.O thanks FCT/MCTES (Portugal) for the individual contract, CEECIND/00648/2017.

Institutional Review Board Statement: Not applicable.

Informed Consent Statement: Not applicable.

Data Availability Statement: The data presented in this study are available on request from the corresponding author.

Conflicts of Interest: The authors declare no conflict of interest.

\section{References}

1. Sun, W.; Guo, S.; Hu, C.; Fan, J.; Peng, X. Recent Development of Chemosensors Based on Cyanine Platforms. Chem. Rev. 2016, 116, 7768-7817. [CrossRef] [PubMed]

2. Zhang, D.; Wang, Z.; Yang, J.; Yi, L.; Liao, L.; Xiao, X. Development of a method for the detection of $\mathrm{Cu}^{2+}$ in the environment and live cells using a synthesized spider web-like fluorescent probe. Biosens. Bioelectron. 2021, 182, 113174. [CrossRef] [PubMed]

3. Wang, J.; Xiao, X.; He, B.; Jiang, M.; Nie, C.; Lin, Y.-W.; Liao, L. A novel resonance fluorescence chemosensor based on the formation of heterobinuclear complex with a di-tetradentate macrocyclic ligand and europium (III) for the determination of uranium (VI). Sens. Actuators B Chem. 2018, 262, 359-364. [CrossRef]

4. Taylor, A.A.; Tsuji, J.S.; Garry, M.R.; McArdle, M.E.; Goodfellow, W.L.; Adams, W.J.; Menzie, C.A. Critical Review of Exposure and Effects: Implications for Setting Regulatory Health Criteria for Ingested Copper. Environ. Manag. 2020, 65, 131-159. [CrossRef]

5. Rehman, K.; Fatima, F.; Waheed, I.; Akash, M.S.H. Prevalence of exposure of heavy metals and their impact on health consequences. J. Cell. Biochem. 2018, 119, 157-184. [CrossRef]

6. Dalmieda, J.; Kruse, P. Metal Cation Detection in Drinking Water. Sensors 2019, 19, 5134. [CrossRef]

7. USA EPA. National Primary Drinking Water Regulations. Available online: https://www.epa.gov/ground-water-and-drinkingwater/national-primary-drinking-water-regulations\#Inorganic (accessed on 1 February 2022).

8. EUR-Lex. Directive (EU) 2020/2184 of the European Parliament and of the Council of 16 December 2020 on the Quality of Water Intended for Human Consumption. Available online: https:/ / eur-lex.europa.eu/eli/dir/2020/2184/oj (accessed on 1 February 2022).

9. USA EPA. National Primary Drinking Water Guidelines, 2009. Epa 816-F-09-004. Available online: https://www.nrc.gov/docs / ML1307/ML13078A040.pdf (accessed on 1 February 2022). 
10. Kruse, P. Review on water quality sensors. J. Phys. D Appl. Phys. 2018, 51, 203002. [CrossRef]

11. Yao, Z.; Huang, B.; Hu, X.; Zhang, L.; Li, D.; Guo, M.; Zhang, X.; Yuan, H.; Wu, H.-C. Colorimetric detection of copper ions based on a supramolecular complex of water-soluble polythiophene and ATP. Analyst 2013, 138, 1649. [CrossRef]

12. Kar, C.; Shindo, Y.; Oka, K.; Nishiyama, S.; Suzuki, K.; Citterio, D. Spirolactam capped cyanine dyes for designing NIR probes to target multiple metal ions. RSC Adv. 2017, 7, 24970-24980. [CrossRef]

13. Strehmel, B.; Schmitz, C.; Kütahya, C.; Pang, Y.; Drewitz, A.; Mustroph, H. Photophysics and photochemistry of NIR absorbers derived from cyanines: Key to new technologies based on chemistry 4.0. Beilstein J. Org. Chem. 2020, 16, 415-444. [CrossRef]

14. Shindy, H.A. Fundamentals in the chemistry of cyanine dyes: A review. Dye. Pigment. 2017, 145, 505-513. [CrossRef]

15. Mishra, A.; Behera, R.K.; Behera, P.K.; Mishra, B.K.; Behera, G.B. Cyanines during the 1990s: A Review. Chem. Rev. 2000, 100, 1973-2012. [CrossRef] [PubMed]

16. Keller, K.; Kampfer, H.; Matejec, R.; Lapp, O.; Krafft, W.; Frenken, H.; Lührig, H.; Scheerer, R.; Heilmann, M.; Meckl, H.; et al Photography. In Ullmann's Encyclopedia of Industrial Chemistry; Wiley-VCH: Weinheim, Germany; Verlag GmbH \& Co. KGaA: Weinheim, Germany, 2000.

17. Della Pelle, G.; Delgado López, A.; Salord Fiol, M.; Kostevšek, N. Cyanine Dyes for Photo-Thermal Therapy: A Comparison of Synthetic Liposomes and Natural Erythrocyte-Based Carriers. Int. J. Mol. Sci. 2021, 22, 6914. [CrossRef] [PubMed]

18. Tang, B.; Huang, H.; Xu, K.; Tong, L.; Yang, G.; Liu, X.; An, L. Highly sensitive and selective near-infrared fluorescent probe for zinc and its application to macrophage cells. Chem. Commun. 2006, 34, 3609-3611. [CrossRef]

19. Tang, B.; Cui, L.J.; Xu, K.H.; Tong, L.L.; Yang, G.W.; An, L.G. A Sensitive and Selective Near-Infrared Fluorescent Probe for Mercuric Ions and Its Biological Imaging Applications. ChemBioChem 2008, 9, 1159-1164. [CrossRef] [PubMed]

20. Slowing, I.I.; Vivero-Escoto, J.L.; Wu, C.-W.; Lin, V.S.-Y.Y. Mesoporous silica nanoparticles as controlled release drug delivery and gene transfection carriers. Adv. Drug Deliv. Rev. 2008, 60, 1278-1288. [CrossRef]

21. Shi, Y.; Wang, R.; Yuan, W.; Liu, Q.; Shi, M.; Feng, W.; Wu, Z.; Hu, K.; Li, F. Easy-to-Use Colorimetric Cyanine Probe for the Detection of $\mathrm{Cu}^{2+}$ in Wilson's Disease. ACS Appl. Mater. Interfaces 2018, 10, 20377-20386. [CrossRef]

22. Liu, B.; Wang, H.; Yang, D.; Tan, R.; Zhao, R.R.; Xu, R.; Zhou, Z.J.; Zhang, J.F.; Zhou, Y. A cyanine-based colorimetric and fluorescent probe for highly selective sensing and bioimaging of phosphate ions. Dye. Pigment. 2016, 133, 127-131. [CrossRef]

23. Wu, D.; Chen, L.; Lee, W.; Ko, G.; Yin, J.; Yoon, J. Recent progress in the development of organic dye based near-infrared fluorescence probes for metal ions. Coord. Chem. Rev. 2018, 354, 74-97. [CrossRef]

24. Marcelo, G.A.; Pires, S.M.G.; Faustino, M.A.F.; Simões, M.M.Q.; Neves, M.G.P.M.S.; Santos, H.M.; Capelo, J.L.; Mota, J.P.; Lodeiro, C.; Oliveira, E. New dual colorimetric/fluorimetric probes for $\mathrm{Hg}^{2+}$ detection \& extraction based on mesoporous SBA-16 nanoparticles containing porphyrin or rhodamine chromophores. Dye. Pigment. 2019, 161, 427-437. [CrossRef]

25. Zhen, D.; Shi, S.; Gao, C.; Kang, Q.; Xiao, X.; Grimes, C.A.; Cai, Q. Bi, Fe, and Ti ternary co-doped $\mathrm{ZrO}_{2}$ nanocomposites as a mass spectrometry matrix for the determination of bisphenol A and tetrabromobisphenol A in tea. Microchim. Acta 2020, 187, 582. [CrossRef] [PubMed]

26. Narayan, R.; Nayak, U.; Raichur, A.; Garg, S. Mesoporous Silica Nanoparticles: A Comprehensive Review on Synthesis and Recent Advances. Pharmaceutics 2018, 10, 118. [CrossRef]

27. Guo, L.; Ping, J.; Qin, J.; Yang, M.; Wu, X.; You, M.; You, F.; Peng, H. A Comprehensive Study of Drug Loading in Hollow Mesoporous Silica Nanoparticles: Impacting Factors and Loading Efficiency. Nanomaterials 2021, 11, 1293. [CrossRef]

28. Galhano, J.; Marcelo, G.A.; Duarte, M.P.; Oliveira, E. Ofloxacin@Doxorubicin-Epirubicin functionalized MCM-41 mesoporous silica-based nanocarriers as synergistic drug delivery tools for cancer related bacterial infections. Bioorg. Chem. 2022, 118, 105470 [CrossRef] [PubMed]

29. Mureseanu, M.; Reiss, A.; Stefanescu, I.; David, E.; Parvulescu, V.; Renard, G.; Hulea, V. Modified SBA-15 mesoporous silica for heavy metal ions remediation. Chemosphere 2008, 73, 1499-1504. [CrossRef]

30. Kumar, R.; Rauwel, P.; Rauwel, E. Nanoadsorbants for the Removal of Heavy Metals from Contaminated Water: Current Scenario and Future Directions. Processes 2021, 9, 1379. [CrossRef]

31. Duarte, F.; Cuerva, C.; Fernández-Lodeiro, C.; Fernández-Lodeiro, J.; Jiménez, R.; Cano, M.; Lodeiro, C. Polymer Micro and Nanoparticles Containing B(III) Compounds as Emissive Soft Materials for Cargo Encapsulation and Temperature-Dependent Applications. Nanomaterials 2021, 11, 3437. [CrossRef] [PubMed]

32. Visaveliya, N.; Hoffmann, C.; Groß, A.; Täuscher, E.; Ritter, U.; Koehler, J.M. Micro-flow assisted synthesis of fluorescent polymer nanoparticles with tuned size and surface properties. Nanotechnol. Rev. 2016, 5, 259-272. [CrossRef]

33. Cuerva, C.; Fernández-Lodeiro, J.; Cano, M.; Capelo-Martínez, J.L.; Lodeiro, C. Water-soluble hollow nanocrystals from selfassembly of AIEE-active Pt(II) metallomesogens. Nano Res. 2021, 14, 245-254. [CrossRef]

34. Bhattacharyya, S.; Prashanthi, S.; Bangal, P.R.; Patra, A. Photophysics and Dynamics of Dye-Doped Conjugated Polymer Nanoparticles by Time-Resolved and Fluorescence Correlation Spectroscopy. J. Phys. Chem. C 2013, 117, 26750-26759. [CrossRef]

35. Conceição, D.; Ferreira, D.; Ferreira, L. Photochemistry and Cytotoxicity Evaluation of Heptamethinecyanine Near Infrared (NIR) Dyes. Int. J. Mol. Sci. 2013, 14, 18557-18571. [CrossRef]

36. Berlman, I.B. Handbook of Fluorescence Spectra of Aromatic Molecules; Academic Press: New York, NY, USA, 1971.

37. Montalti, M.; Credi, A.; Prodi, L.; Teressa, M.G. Handbook of Photochemistry, 3rd ed.; Taylor \& Francis: Bocan Raton, FL, USA, 2006. 
38. Bouteiller, C.; Clavé, G.; Bernardin, A.; Chipon, B.; Massonneau, M.; Renard, P.-Y.; Romieu, A. Novel Water-Soluble Near-Infrared Cyanine Dyes: Synthesis, Spectral Properties, and Use in the Preparation of Internally Quenched Fluorescent Probes. Bioconjug. Chem. 2007, 18, 1303-1317. [CrossRef] [PubMed]

39. Yang, W.; Chen, X.; Su, H.; Fang, W.; Zhang, Y. The fluorescence regulation mechanism of the paramagnetic metal in a biological HNO sensor. Chem. Commun. 2015, 51, 9616-9619. [CrossRef] [PubMed]

40. Morais, N.A.; Fernandes, L.; Ariana-Machado, J.; Capelo, J.L.; Lodeiro, C.; Oliveira, E. An unusual emissive and colorimetric copper (II) detection by a selective probe based on a pseudo-crown cysteine dye: Solution and gas phase studies. Inorg. Chem. Commun. 2017, 86, 299-303. [CrossRef]

41. Gans, P.; Sabatini, A.; Vacca, A. Investigation of equilibria in solution. Determination of equilibrium constants with the HYPERQUAD suite of programs. Talanta 1996, 43, 1739-1753. [CrossRef]

42. Oliveira, E.; Santos, H.M.; Jorge, S.; Rodríguez-González, B.; Novio, F.; Lorenzo, J.; Ruiz-Molina, D.; Capelo, J.L.; Lodeiro, C. Sustainable synthesis of luminescent CdTe quantum dots coated with modified silica mesoporous nanoparticles: Towards new protein scavengers and smart drug delivery carriers. Dye. Pigment. 2019, 161, 360-369. [CrossRef]

43. Xu, Y.; Axe, L. Synthesis and characterization of iron oxide-coated silica and its effect on metal adsorption. J. Colloid Interface Sci. 2005, 282, 11-19. [CrossRef]

44. Wang, Y.; Yan, Y.; Cui, J.; Hosta-Rigau, L.; Heath, J.K.; Nice, E.C.; Caruso, F. Encapsulation of Water-Insoluble Drugs in Polymer Capsules Prepared Using Mesoporous Silica Templates for Intracellular Drug Delivery. Adv. Mater. 2010, 22, 4293-4297. [CrossRef] 